\title{
Capital Market Equilibrium With Imperfect Competition: The Case of the ECB's Asset Purchase Programme
}

\author{
${\text { Christian } \text { Koziol }^{1} \text { (D) } \cdot \text { Werner Neus }}^{2}$
}

Received: 30 October 2019 / Accepted: 12 May 2020 / Published online: 27 May 2020

(C) The Author(s) 2020

\begin{abstract}
We set up a multiperiod, CAPM-type model with imperfect competition between investors in case of an additional price-insensitive market participant. The motivation for this additional actor comes from the ECB's announcement to buy a substantial amount of securities "whatever it takes" which reflects the willingness to trade in a entirely price-inelastic way. Our model explains the effects on demand functions, equilibrium prices, portfolio holdings and investors' expected utility. The interaction of price-inelastic additional demand by the ECB, on the one hand, and imperfect competition, on the other hand, causes differentiated results regarding timing strategies, development of prices over time, and utility implications.
\end{abstract}

Keywords Price-inelastic demand · Asset pricing - Imperfect competition · Market liquidity

JEL-Classifications D $43 \cdot$ G 12

\section{Introduction}

The asset purchase programme (APP) carried out by the European Central Bank (ECB) between March 2015 and December 2018 has gained widespread attention

C. Koziol

christian.koziol@uni-tuebingen.de

W. Neus

werner.neus@uni-tuebingen.de

1 Department of Finance, University of Tuebingen, Nauklerstr. 47, 72074 Tuebingen, Germany

2 Department of Banking, University of Tuebingen, Nauklerstr. 47, 72074 Tuebingen, Germany 
for two reasons: First, the total market volume of acquired bonds attributes to more than 2.5 trillion EUR and is, therefore, of a predominant magnitude. Related to the size of the total sovereign bond market, the ECB acquired almost $40 \%$ of the outstanding bond issuances within the eurozone.

Second, this extreme activity of the ECB has offset traditional market forces within the fixed income trading. In the first place, the bond prices have increased so that the yield to maturity of the corresponding bonds and likewise interest rates, in general, have significantly declined. More than that, the relation between prices and other asset classes has sharply changed due to the fundamentally different environment. As of November 2019, further buybacks with a monthly volume equal to 20 billion EUR have been announced. Given the Corona crisis, the amount has been substantially extended, again.

With this bond acquisition behavior, the ECB has become a major player at the capital market, acting in an unusual way relative to the other investors. While traditional equilibrium pricing models assume market participants to behave in accordance with their individual preferences, beliefs and endowments, the ECB is a fundamentally different player acting in a price-insensitive way according to a communicated schedule.

This observation of a new type of market participant trading large volumes regardless of the price is the motivation for our paper. Our aim is to analyze the effects of a suchlike price-insensitive market participant for an equilibrium asset pricing model. In particular, we can have the notion that this market participant is the ECB but does not need to be: Alternatively, investors following a frequent asset savings plan also exhibit these characteristics. Moreover, we can also think of companies carrying out a stock repurchase programme approved by the general meeting. For reasons of illustrative simplification, we will use the term ECB as a general abbreviation for all types of price-insensitive investors following a prespecified schedule and do not exclusively refer to the European Central Bank and their particular characteristics within our equilibrium.

In a theoretical model with perfect competition, the price effect of the ECB's interventions is like that from a reduction of units held by the other investors. Therefore, only the intended volume of the ECB's repurchases matters in order to impact asset prices rather than the point in time of trading.

However, if trading takes place under imperfect competition, e.g., if investors are strategically aware of the price impact of their trades, markets are not perfectly liquid so that prices might be additionally impacted by the ECB's transactions beyond the pure reduction effect of outstanding bond volume. This characteristic is highly consistent with the bond market which is dominated by a limited number of large investors.

In order to understand the ECB's impact on asset prices, we integrate a market participant representing the ECB who acts completely price-inelastic into a model of capital market equilibrium. Because of its well-known characteristics and implications, we choose the capital asset pricing model (CAPM) as the initial framework for our analysis. On this basis, we can identify the implications of a price-inelastic behavior on demand functions, equilibrium prices, optimal portfolios holdings and 
the expected utility of capital market investors. ${ }^{1}$ In order to capture liquidity effects and the change of liquidity over time in our equilibrium asset pricing model, we assume strategic investors taking care of their price effect of their demand at two trading dates. ${ }^{2}$

In particular, our theoretical model aims at answering the following questions:

- How do trades by the ECB affect market prices?

- Does the timing (early or late) of the ECB's trades impact market prices? In other words, we want to distinguish whether the ECB's announcement of a purchase programme or the execution of it has a more severe price effect.

- How does the demand of other investors change when the ECB is present?

- What do the ECB's activities mean for the investors' expected utility?

With these research questions, this paper provides insights for portfolio management and theoretical asset pricing in a new framework adjusted to recent challenges. Even though we address the ECB as an example, we do not aim at contributing either to central bank behavior nor to monetary economics.

Our model relies on a slightly modified version of the capital asset pricing model (CAPM). As it is well known, the Mossin (1973) representation of the ubiquitous CAPM is more suitable for theoretical analyses than the basic Sharpe (1964) model. We enrich the Mossin model by three additional features: First, there is a second trading round in order to capture timing effects driven by a change of market liquidity over time. Second, the market participants consider the price effects of their trading instead of acting as price-takers. Third, we introduce a market participant acting completely price-inelastic denoted as ECB.

In order to focus on these essentials, we remove some typical CAPM ingredients to keep the analysis concise: diversification of different types of risky securities, different degrees of risk aversion, and heterogenous expectations on the assets' return parameters (the latter actually not being part of the basic CAPM).

Multiperiod capital market equilibria have been analyzed in a discrete time and a continuous time framework (see Stapleton and Subrahmanyam 1978; and Merton 1973; respectively). The consideration of two trading rounds allows us to capture both announcement effects (prior to ECB's interventions) as well as price effects (subsequent to ECB's trading).

Imperfect competition, most notably, has been analyzed by Lindenberg (1979). ${ }^{3}$ He extends the Mossin-CAPM by including some price affectors in addition to the usual price takers. Solving the model, Lindenberg explicitly considers the influence one investor exerts on the other investors' decisions (conjectural variations). He does not, however, come to an explicit solution for security prices and individual portfolios except for the case of a single price affector. We, therefore, employ the Nash equilibrium concept to reveal the unique equilibrium. To the best of our knowledge,

\footnotetext{
1 We use the term "investor" for all market participants except for the ECB-type participant.

2 Throughout the paper, "demand" characterizes the intended holdings, not the shifting of the portfolio. In a secondary market, the overall supply is identical to the set of outstanding securities.

3 Other papers, including Rudolph (1982) and Hirth (1997), discuss special cases of the general model. In addition, the latter integrates the effects of a second trading round.
} 
there is virtually no example for an ECB-like price-inelastic behavior in the literature as analyzed in our framework.

As is well-known, CAPM prices are determined in a Walrasian auction. Another strand of literature focuses on alternative forms of market microstructure, for example, a market clearing by the inclusion of noise traders (Kyle 1989) or additionally introduced market makers (Kyle 1985; Subrahmanyam 1991; Spiegel and Subrahmanyam 1992). The main topics of these contributions are market liquidity and information aggregation via the pricing mechanism. Excluding the heterogeneous information topic and emphasizing the liquidity aspect, Heumann (2007) comes quite close to our analysis. Even if the two approaches referred to (CAPM-type modeling vs. market microstructure) considerably differ in their respective starting points, they end up with virtually the same results when adopted to comparable market conditions.

The main contribution of our paper is to extend the established models of imperfect competition by an ECB-like participant who demands a pre-specified schedule of assets at both trading dates. Beside a general analysis, we distinguish between the case with ECB trades taking place early (period 1) or only late (period 2). The investigation of this market structure reveals the following findings:

- The ECB's acquisitions of an asset increase its price more strongly than a pure reduction of the initial endowment (which was the price effect of the ECB for perfect competition).

- Late purchases by the ECB imply a stronger price increase than early trades of the same size (as long as no information is revealed between trading dates).

- Even though the investors' period 1 demand functions are shifted upward due to the ECB's purchases in period 2, their trading volume remains unaffected in equilibrium.

- An additional demand by the ECB always causes utility losses on part of the investors.

The remainder of the paper is organized as follows. In Sect. 2, we present the two-period reference model with imperfect competition in the absence of the ECB's purchases. In the next step, we extend this framework for an arbitrary, credible trading strategy of the ECB in Sect. 3. Sect. 4 analyzes the ECB's timing effects on equilibrium prices, demand, trading volume and investors' utility. In Sect. 5, we discuss a generalization of our model incorporating additional information at the end of period 1. Sect. 6 concludes. All technical developments are shown in the appendix.

\section{The Reference Model}

\subsection{The Setting}

For our analysis, we consider an equilibrium pricing model with imperfect competition. The analytical framework rests on Mossin (1973) and extends his approach by imperfect competition, to be more precise a Cournot-Nash behavior of the investors. 
We analyze a capital market with $n$ investors. In the market, two assets are traded, a riskless asset whose return is normalized to zero and a risky security. There are two trading periods. Thus, the investors can adjust their initial individual portfolios in two steps considering the activities of all involved market participants. The risky asset's terminal value $\widetilde{v}$ at the end of the second period is normally distributed with mean $\mu$ and variance $\sigma^{2}$. These parameters are common knowledge. The investors' utility function is exponential, $u\left(\widetilde{w}_{i 2}\right)=-\exp \left\{-\theta \widetilde{w}_{i 2}\right\}$, where $\theta>0$ is the (constant) Pratt-Arrow coefficient of absolute risk aversion and $\widetilde{w}_{i 2}$ is investor $i$ 's terminal wealth. Given the normally distributed asset value $\widetilde{v}$, the investors maximize the mean-variance certainty equivalent $\varphi_{i}=\mathrm{E}\left\{\widetilde{w}_{i 2}\right\}-\frac{1}{2} \theta \operatorname{Var}\left\{\widetilde{w}_{i 2}\right\}$. Each investor is endowed with an individual legacy portfolio, i.e. a certain number of the risky asset and the riskless security $\left(\bar{x}_{i 0}\right.$ and $\bar{y}_{i 0}$, respectively). There are no short-selling restrictions, and the securities are perfectly divisible. Finally, we normalize the number of risky securities outstanding to one.

As special features, we have (1) two trading rounds rather than one and (2) investors not acting as price takers but considering the price impact of their demand. Overall, the approach is compatible with the previously discussed related literature, most of all Lindenberg (1979).

It is essential for our purposes that investors have an incentive to revise their portfolios. Given the same degree of risk aversion on the part of the different investors, the optimal target portfolios consist of the same share, $\frac{1}{n}$, in the risky asset's free float. ${ }^{4}$ The trading motive is, therefore, introduced by some deviation in the legacy portfolio. Later on, we will refer to investors as sellers or buyers if $\bar{x}_{i 0}>\frac{1}{n}$ or $\bar{x}_{i 0}<\frac{1}{n}$, respectively. This exposition reveals the distortion caused by imperfect competition and the ECB in the easiest and most transparent way. In the following, we are mostly interested in the investors' equilibrium portfolios $x_{i t}^{*}$ and prices $p_{t}^{*}$ $(i=1, \ldots, n ; t=1,2)$.

The initial wealth of investor $i$ is represented by the value of her initial endowment: 6

$$
\bar{a}_{i}=\bar{x}_{i 0} p_{1}+\bar{y}_{i 0}
$$

Her terminal wealth consists of her share in the risky asset and her holding of the riskless asset:

$$
\widetilde{w}_{i 2}=x_{i 2} \widetilde{v}+y_{i 2}
$$

\footnotetext{
${ }^{4}$ Within later sections, the free float may differ from the number of outstanding securities by the ECB's purchases.

${ }^{5}$ The general rule for optimal risk sharing follows the share of the individual risk tolerance, i.e. the inverse of the absolute risk aversion, in the sum of the risk tolerances of all investors (cf. Wilson 1968). Because of homogenous risk preferences, risk should be equally shared between all investors.

${ }^{6}$ Any equation indexed by $i$ has to hold for every $i$-th investor. For ease of exposition, we skip this notation.
} 
Substituting the period-specific budget constraints

$$
\begin{aligned}
& y_{i 1}=\bar{y}_{i 0}-\left(x_{i 1}-\bar{x}_{i 0}\right) p_{1} \\
& y_{i 2}=y_{i 1}-\left(x_{i 2}-x_{i 1}\right) p_{2}
\end{aligned}
$$

for the riskless asset, we obtain for the investor $i$ 's terminal wealth

$$
\widetilde{w}_{i 2}=x_{i 2}\left(\widetilde{v}-p_{2}\right)+x_{i 1}\left(p_{2}-p_{1}\right)+\bar{a}_{i}
$$

An increase in wealth is caused by the respective holdings in the two periods and positive price changes or favorable realizations of the risky asset's terminal value.

Each investor maximizes her certainty equivalent

$$
\varphi_{i}=x_{i 2}\left(\mu-p_{2}\right)+x_{i 1}\left(p_{2}-p_{1}\right)+\bar{a}_{i}-\frac{1}{2} \theta \sigma^{2} x_{i 2}^{2} .
$$

\subsection{Intertemporal Equilibrium}

We solve the two-period model by backward induction. At the beginning of the second period, the price $p_{1}$ and the portfolios $x_{i 1}$ are given. Investor $i$ 's first-order condition reads

$$
\frac{\partial \varphi_{i}}{\partial x_{i 2}}=\left(\mu-p_{2}\right)-\left(x_{i 2}-x_{i 1}\right) \frac{d p_{2}}{d x_{i 2}}-\theta \sigma^{2} x_{i 2}=0 \text {. }
$$

A crucial term for the further derivation of the equilibrium is the impact of a marginally increased demand on the price. Obviously, under perfect competition the effect equals zero. With imperfect competition, we expect a positive derivative. Lindenberg (1979) as the most similar approach to ours uses the total derivative as starting point:

$$
\frac{d p_{2}}{d x_{i 2}}=\frac{\partial p_{2}}{\partial x_{i 2}}+\sum_{j \neq i} \frac{\partial p_{2}}{\partial x_{j 2}} \frac{\partial x_{j 2}}{\partial x_{i 2}}
$$

and solves for different equilibrium outcomes depending on the investors' "conjectural behavior". In a Nash equilibrium, however, by construction there is no effect of one investor's demand on the other investors' demand because one-sided deviations from equilibrium must not pay off. The remaining partial derivative may be constant, increasing or decreasing. In what follows, we refrain from analyzing a non-linear form of the function $p_{2}\left(x_{i 2}\right)$. Restricting ourselves to equilibria with a linear pricequantity schedule, we will show there is a unique Cournot-Nash equilibrium within this class of demand functions. ${ }^{7}$ We do not make any statement on the possible exis-

\footnotetext{
7 An alternative approach to solving for an equilibrium stands more in the tradition of the Kyle (1989) model of insider trading (which also has been employed by Heumann (2007)). They model the capital market under imperfect competition as a divisible good auction assuming linear bidding strategies. Throughout, the results are the same.
} 
tence of other equilibria with a non-linear demand. Neither within the CAPM-type approach (see, e.g., Hirth and Walther 2018) nor within the microstructure literature (see, e.g., Kyle 1985) there is any paper dealing with properties of an eventual nonlinear equilibrium. A forteriori, it is quite unclear whether there exist other equilibria at all.

Given linear inverse demand functions, $p_{t}=\gamma_{t}+\beta_{t} \sum_{i} x_{i t}$, we always have $\frac{\partial p_{2}}{\partial x_{i 2}}=\beta_{2}$ and can solve the first-order condition for the optimal individual demand

$$
x_{i 2}\left(p_{2}, x_{i 1}\right)=\frac{\left(\mu-p_{2}\right)+x_{i 1} \beta_{2}}{R+\beta_{2}} .
$$

where $R \equiv \theta \sigma^{2}$ comprises the effects of risk and risk aversion. Solving for the equilibrium value of $\beta_{2}$ (cf. Appendix 1) yields ${ }^{8}$

$$
\beta_{2}=\frac{R}{n-2} \text {. }
$$

$\beta_{2}$ can be seen as an inverse measure for market liquidity in period 2 . The higher $\beta_{2}$, the stronger is the price impact of demand, and the lower is market liquidity. In equilibrium, (quite naturally) liquidity increases with the number of investors. Increasing risk or increasing risk aversion, instead, implies decreasing liquidity. A strong preference for coming close to the optimal risk sharing leads to a less price sensitive demand. In liquid markets, prices hardly react to changes in demand or supply. In turn, demand shows a high price elasticity. In case of high risk or high-risk aversion, however, demand is mainly driven by risk considerations and not by price effects. In other words, the market is rather illiquid. Inversely, if there was no risk, the market would be perfectly liquid even in the presence of scarce competition.

Next, we solve for the equilibrium price of the risky asset. Summing up the investors' first-order conditions

$$
\sum_{i=1}^{n} \frac{\partial \varphi_{i}}{\partial x_{i 2}}=n\left(\mu-p_{2}\right)-R \underbrace{\sum_{i=1}^{n} x_{i 2}}_{=1}-\beta_{2} \underbrace{\sum_{i=1}^{n}\left(x_{i 2}-x_{i 1}\right)}_{=1-1=0}=0
$$

and using the market clearing conditions as depicted by the curly brackets we can solve for the equilibrium price

$$
p_{2}^{*}=\mu-\frac{R}{n} \text {. }
$$

Here, $p_{2}^{*}$ fully corresponds to the standard CAPM with perfect competition, i.e. price-taking investors. Remarkably, the price sensitivity reflected by $\beta_{2}$ does not have any impact on the second-period equilibrium price. (This result will no longer hold when we add the ECB's APP to the model. Cf. Sects. 3 and 4).

\footnotetext{
8 We note that a framework with $n=2$ investors does not result in an equilibrium. This property has already been identified by Kyle (1989, p. 328) and Heumann (2007, p. 73).
} 
Finally, we are interested in the investors' equilibrium portfolios $x_{i 2}^{*}$. Inserting the equilibrium price (3) into individual demand function (2), we obtain

$$
x_{i 2}^{*}\left(x_{i 1}\right)=\frac{1}{n}\left(1-q_{2}\right)+x_{i 1} q_{2},
$$

where $q_{2} \equiv \frac{\partial x_{i 2}}{\partial x_{i 1}}=\frac{\beta_{2}}{R+\beta_{2}}=\frac{1}{n-1}$ (cf. appendix 1). The optimal holding can be described as the weighted average of the second-period initial holding $x_{i 1}$ and the optimal risk-sharing rule $\frac{1}{n}$. The deviation from optimal risk sharing $\left(q_{2}\right)$ increases if market liquidity decreases because the cost to arrive at the optimal risk sharing increases. In equilibrium, however, the extent to which this effect is present does not depend on the risk itself.

The first-period calculus is basically the same as for period 2. In maximizing the certainty equivalent (1), however, the second-period price $p_{2}^{*}$ and the optimal portfolio adjustment rule $x_{i 2}^{*}\left(x_{i 1}\right)$ will be anticipated. When choosing $x_{i 1}$, investor $i$ considers the impact on her future portfolio choice.

Starting from the first-order condition

$$
\frac{\partial \varphi_{i}}{\partial x_{i 1}}=\frac{\partial x_{i 2}}{\partial x_{i 1}} \frac{R}{n}+\left(\mu-\frac{R}{n}-p_{1}\right)-\left(x_{i 1}-\bar{x}_{i 0}\right) \frac{\partial p_{1}}{\partial x_{i 1}}-R x_{i 2} \frac{\partial x_{i 2}}{\partial x_{i 1}}=0
$$

and using $q_{2}$ as defined above as well as $\beta_{1} \equiv \frac{\partial p_{1}}{\partial x_{i 1}}$, we obtain the demand schedule

$$
x_{i 1}\left(p_{1}\right)=\frac{\mu-p_{1}+\bar{x}_{i 0} \beta_{1}}{\beta_{1}+R q_{2}^{2}}-\frac{1}{n} \frac{\left(1-q_{2}^{2}\right) R}{\beta_{1}+R q_{2}^{2}} .
$$

In equilibrium, $\beta_{1}$ takes the value (cf. Appendix 1)

$$
\beta_{1}=\frac{R q_{2}^{2}}{(n-2)} \text {. }
$$

Notice that the price sensitivity for individual trades at time $t=1, \beta_{1}$, is below that at time $t=2, \beta_{1}<\beta_{2}$, i.e. in period 1 the market is more liquid than in period 2. Intuitively, the liquidity at time $t=1$ is supposed to be higher because there is still a further trading opportunity at the later date $t=2$. Moreover, there is no risk to be revealed in period 1 and the second-period risk enters liquidity only via anticipation of the second-period trades.

Using the first-period market clearing conditions, the equilibrium price is

$$
p_{1}^{*}=\mu-\frac{R}{n} \text {. }
$$

No price change over time can be observed.

Finally, using the equilibrium price, the optimal first-period security holding is

$$
x_{i 1}^{*}\left(\bar{x}_{i 0}\right)=\frac{1}{n}\left(1-q_{1}\right)+\bar{x}_{i 0} q_{1},
$$


where $q_{1} \equiv \frac{\partial x_{i 1}}{\partial \bar{x}_{i 0}}=\frac{1}{n-1}=q_{2}=q$ (cf. Appendix 1). The portfolio adjustment rule is the same as in period 2. Again, we have a weighted average between the beginning-of-period holding and the optimal risk sharing with the same weights as in period 2 .

The main driver of the results is the investors' need to adjust their individual portfolios caused by the imbalance of the endowment and optimal risk sharing. Restating eqs. (4) and (7) reveals

$$
\begin{aligned}
& x_{i 1}^{*}=\frac{1}{n}-\xi_{i} q, \\
& x_{i 2}^{*}=\frac{1}{n}-\xi_{i} q^{2},
\end{aligned}
$$

where $\xi_{i} \equiv \frac{1}{n}-\bar{x}_{i 0}$ is a measure for the initial imbalance, i.e. the need to adjust the initial portfolio. A certain share $1-q$ of this imbalance will be captured in the first period. The same share of the remaining imbalance is settled in the second period. A steady increase of the number of trading periods implies a convergence of the final portfolio to optimal risk sharing. ${ }^{9}$

A final interesting remark is about the investors' expected utility. We have

$$
\varphi_{i}^{*}=\bar{a}_{i}+\frac{R}{2 n^{2}}\left(1-\lambda_{i}^{2}\right),
$$

where $\lambda_{i} \equiv n \xi_{i} q^{2}$ measures the overall distortion caused by the initial imbalance and the reluctant adjustment of the portfolio. In case there is no initial imbalance of the endowment $\left(\xi_{i}=0\right)$ or there is perfect competition between investors $(q=0)$ we arrive at the well-known Pareto-optimal risk sharing and a maximum individual utility. Notably, the sign of the initial imbalance does not matter.

Up to here, the questions of interest have been the deviations that imperfect competition causes compared to the standard CAPM. There is no impact on the equilibrium prices, which are constant over the two periods. The differences are actually driven by the price affecting the behavior of the investors. The individual portfolios are not adjusted the way they should be because the investors do not want to affect prices in an unfavorable way. At the end, imperfect competition is some kind of built-in "brake" to trading activities (Hirth 1997).

\section{Introducing the ECB-General Model}

Starting with this section, we introduce an additional market participant, the ECB. This investor buys a certain amount $\left(\Delta_{t}>0\right)$ of the risky asset within the respective periods $t=1$ and $t=2$ whatever it takes. We can address the matter of timing, i.e. the different effects of the ECB buying "early" (within period 1) or "late" (within period 2) or both.

Here, some remarks on the institutional background of the ECB's APP seem to be appropriate. On the one hand, the ECB's decisions refer to a limited investment

\footnotetext{
9 This result has already been observed by Hirth and Walther (2018).
} 
measured in money units in a wider class of assets (public sector purchase programme, corporate sector purchase programme, ...). On the other hand, referring to a single issue, there are purchase limits measured in issue shares. We, therefore, define our $\Delta_{t}$ 's as shares of the securities outstanding amount instead of some fixed money value. Furthermore, due to a strictly monotonous and continuous relationship between trading volume $p \Delta$ and traded units $\Delta$, the variables could be translated into one another-however at the costs of implicit instead of explicit solutions.

Regarding the ECB's trading strategies, it is important that its activities are publicly known. As credibility is a crucial matter for any central bank, there is no need of questioning the execution of an announced purchase program. Therefore, problems regarding both time-inconsistent central bank behavior such as those in Klein (2018) and the effectiveness of communication as discussed by Blinder et al. (2008) are ruled out in our theoretical framework.

The results of the model can be derived analogously to the reference model. Therefore, we omit the calculations. Instead, we solely present the resulting effects on the first- and second-period demand functions, prices, optimal portfolios as well as on investors' expected utility. ${ }^{10}$ Furthermore, we only give some preliminary comments on the general results while we will discuss the solutions for two examples in-depth within Sect. 4.

\subsection{Demand Functions}

$$
\begin{gathered}
x_{i 2}\left(p_{2}, x_{i 1}\right)=\frac{\mu-p_{2}+x_{i 1} \beta_{2}}{R+\beta_{2}} \\
x_{i 1}\left(p_{1}, \bar{x}_{i 0}\right)=\left\{\frac{\mu-p_{1}+\bar{x}_{i 0} \beta_{1}}{\beta_{1}+R q^{2}}-\frac{1}{n} \frac{\left(1-q^{2}\right) R}{\beta_{1}+R q^{2}}\right\}+\frac{\Delta_{1}}{n} \frac{\left(1-q^{2}\right) R}{\beta_{1}+R q^{2}}+\frac{\Delta_{2}}{n} \frac{(1+q) R}{\beta_{1}+R q^{2}}
\end{gathered}
$$

The demand functions allow to state some important interim results:

Lemma 1 (The ECB, Liquidity and Individual Portfolio Restructuring) The ECB's activities do not have any impact on the relation between the prices and the other investor's demand, i.e. market liquidity $\left(\frac{\partial \beta_{t}}{\partial \Delta_{s}}=0\right.$, for $\left.s, t=1,2\right)$. Furthermore, the relation between beginning-of-period holdings and individual demand does not change $\left(\partial\left(\frac{\partial x_{i t}}{\partial x_{i t-1}}\right) / \partial \Delta_{s}=0\right.$ for $\left.s, t=1,2\right)$. I.e., the relation $q_{2}=q_{1}=\mathrm{q}$ continues to hold. Furthermore, the ECB's additional demand just causes an upward shift of the other investors' demand functions in $t=1$ and no change at all in $t=2$.

Interestingly, the second-period demand functions do not at all depend on the ECB's activities, even including late trades. But, of course, in equilibrium the function is evaluated at a different point because the second-period price is affected. Different from period 2, the ECB's activities have an impact on the first-period demand function. The investors anticipate the influence of the ECB's purchases $\left(\Delta_{t}\right)$ which enter the demand function via the second-period price and the effect of the

10 A sketch of the derivations is provided within appendix 2. 
first-period demand on the second-period demand. Quite remarkably, the impact of $\Delta_{2}$ on $x_{i 1}$ is even stronger than the impact of $\Delta_{1}: \frac{\partial x_{i 1}}{\partial \Delta_{2}}>\frac{\partial x_{i 1}}{\partial \Delta_{1}}$.

\subsection{Equilibrium Prices}

The equilibrium prices can be written in a general form using certain pricing coefficients for the ECB's purchase variables:

$$
\begin{aligned}
& p_{1}^{*}=\mu-\frac{1}{n}\left(R-\delta_{11} \Delta_{1}-\delta_{21} \Delta_{2}\right), \\
& p_{2}^{*}=\mu-\frac{1}{n}\left(R-\delta_{12} \Delta_{1}-\delta_{22} \Delta_{2}\right) .
\end{aligned}
$$

Defining $\delta_{s t} \equiv n \frac{\partial p_{t}^{*}}{\partial \Delta_{s}}$ as marginal impact of $\Delta_{s}$ on price $p_{t}^{*}(s, t=1,2)$, we have

$$
\begin{aligned}
& \delta_{11}=R+\beta_{1}, \\
& \delta_{12}=R, \\
& \delta_{21}=R+(1-q) \beta_{2}, \\
& \delta_{22}=R+\beta_{2} .
\end{aligned}
$$

Inserting for the equilibrium values of $q$ and $\beta_{t}$ shows

$$
\delta_{22}>\delta_{21}>\delta_{11}>\delta_{12}=1>0
$$

generally holds true. In line with intuition (and in line with the ECB's intention), the positive coefficients indicate that an additional demand by the ECB always causes a higher price level. While $\Delta_{2}$ affects $p_{2}^{*}$ more than $p_{1}^{*}$, the reverse holds true for $\Delta_{1}$. I.e., the additional demand affects the current equilibrium price more than the previous or future price, respectively.

Quite remarkably, all except for one pricing coefficients exceed the value of $R$. Therefore, the price increase is higher if the ECB announces a future extraction of securities from the market compared to the case where the same amount of securities $\Delta=\Delta_{1}+\Delta_{2}$ is withdrawn before trading starts.

Another interesting question is the price development over time. We have

$$
p_{2}^{*}-p_{1}^{*}=\frac{1}{n}\left(\left(\delta_{12}-\delta_{11}\right) \Delta_{1}+\left(\delta_{22}-\delta_{21}\right) \Delta_{2}\right) \text {. }
$$

Result 1 (ECB Trade and Price Paths) "Late" purchases by the ECB imply increasing prices $\left(\delta_{22}>\delta_{21}\right)$ while an "early" demand comes along with decreasing prices $\left(\delta_{12}<\delta_{11}\right)$.

A striking and maybe even puzzling effect is the generally stronger price effect of a late purchase compared to an early purchase. A first intuition might be that the purchase timing should not matter at all because there is not so much change in the investors' portfolio decisions: no change in information, no change in preferences, no change in the outstanding free float at the end of period 2. So why does the timing matter? The answer is derived from Lemma 1 above: The portfolio adjustment rule and the market liquidity are not affected by the ECB's purchases. The decrease in liquidity is caused by imperfect competition and the optimal adjustment process in 
the investors' portfolios following some exogenous shock (in our model: the imbalanced legacy portfolio). The strategic interaction induced by imperfect competition causes the liquidity to decrease over time which in turn implies a stronger price effect of late trades by the ECB. In Sect. 5, we discuss a generalization of our model incorporating additional information at the end of period 1 and address the question if this effect alters some of the relations.

One might further ask why an anticipated deterministic price change can take place at all and does not allow for arbitrage opportunities. Different from arbitrage transactions in perfectly competitive markets, the investors specified in our economy cannot carry out isolated marginal transactions at given prices. Instead, the price impact of a proposed arbitrage transaction also affects the price of the other traded units unfavorably.

We can formally illustrate this for an ECB strategy acquiring a share $\Delta$ of the asset at time $t=2$ only and one particular investor initially holding $1 / n$ of the assets. Hence, she will optimally sell $\Delta / n$ units at time $t=2$ at a price $p_{2}^{*}$ and not trade at the equilibrium price $p_{1}^{*}$ in $t=1$ at all. Comparing the equilibrium prices at time $t=1$ and $t=2$, we obtain a deterministic price increase over time equal to $p_{2}^{*}-p_{1}^{*}=\frac{q \beta_{2}}{n} \Delta$. For this reason, we allow the investor to buy $x \geq 0$ units at time $t=1$ and to sell $x+\Delta / n$ units at time $t=2$ rather than $\Delta / n$ units. The deterministic net payment at time $t=2$ from trading at both trading dates is then:

$$
\left(p_{2}^{*}-\beta_{2} x\right)\left(x+\frac{\Delta}{n}\right)-\left(p_{1}^{*}+\beta_{1} x\right) x .
$$

Due to the additional trading volume $x$ at time $t=1$, the price for the investor increases by $\beta_{1}$ per additional unit, while at time $t=2$ the additional selling volume reduces the price by $\beta_{2}$ per each of the $x$ additional units. Plugging in the corresponding values for equilibrium prices at both dates and the price sensitivities $\beta_{1}$ and $\beta_{2}$, we obtain:

$$
\left(p_{2}^{*}-\beta_{2} x\right)\left(x+\frac{\Delta}{n}\right)-\left(p_{1}^{*}+\beta_{1} x\right) x=p_{2}^{*} \frac{\Delta}{n}-\frac{\Delta}{n}(1-q) \beta_{2} x-\left(\beta_{1}+\beta_{2}\right) x^{2} .
$$

Since the difference takes its maximum value for $x=0$, it is optimal not to conduct any "arbitrage transaction" with $x>0$ at all. As a result, the market is arbitrage-free, as no investor has an incentive to deviate from the equilibrium holdings despite deterministic price changes. 


\subsection{Equilibrium Portfolios}

Inserting the equilibrium prices into the demand functions yields the following relations for optimum portfolios:

$$
\begin{gathered}
x_{i 2}^{*}\left(x_{i 1}\right)=\frac{1-\Delta_{1}}{n}(1-q)+x_{i 1} q-\frac{\Delta_{2}}{n}, \\
x_{i 1}^{*}=\frac{1}{n}-\xi_{i} q-\frac{\Delta_{1}}{n}, \\
x_{i 2}^{*}=\frac{1}{n}-\xi_{i} q^{2}-\frac{\Delta_{1}+\Delta_{2}}{n} .
\end{gathered}
$$

Obviously, the ECB's additional demand just adds another component to the transparent and plausible structure of equilibrium holdings: The additional demand is compensated for by an equally divided reduction of holdings by the investors. The other component, i.e. the weighted average between beginning-of-period holding and optimal risk sharing has already been discussed in Sect. 3. Again, it is the limited liquidity caused by imperfect competition which prevents the investors from ending up with optimal risk sharing. Another observation deserves to be pointed out: Depending on the degree of the initial imbalance and the extent of the ECB's transaction in the different periods, possibly some investors buy in the first period and sell afterward or vice versa.

Overall, we see a twofold effect of the ECB's late $\Delta_{2}$ on the investor's first-period demand. First, eq. (8) indicates that the investor $i$ 's demand function $x_{i 1}\left(p_{1}, \bar{x}_{i 0}\right)$ is shifted upward for some given price $p_{1}$. Second, the announcement of $\Delta_{2}$ causes an increase in the first-period price $p_{1}^{*}$. In equilibrium, the demand function effect and the price effect just cancel out so that the equilibrium holdings $x_{i 1}^{*}$ are not affected by the ECB's later demand. Fig. 1 illustrates these relations.

Similarly, the ECB's first-period demand $\Delta_{1}$ does not impact the equilibrium adjustments of the investors' portfolios $\Delta x_{i 2}^{*}=x_{i 2}^{*}-x_{i 1}^{*}$ in period 2 .

Fig. 1 Impact of $\Delta_{2}$ on $x_{i 1}$

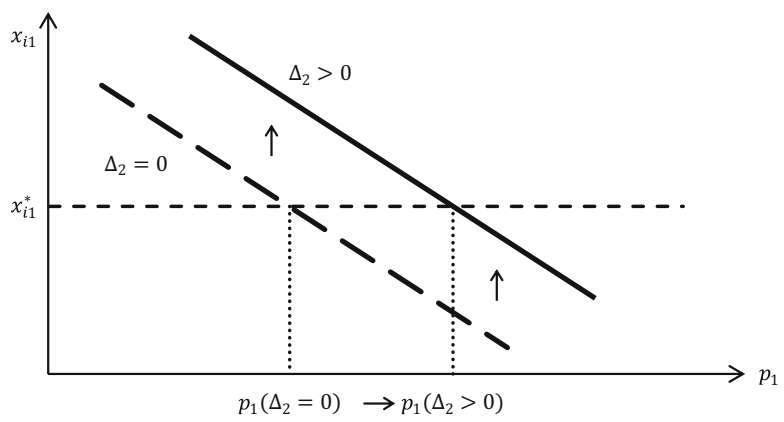




\subsection{Investors' Expected Utility}

Even though it is a bit cumbersome, we present the general solution for the investors' utility: ${ }^{11}$

$$
\begin{aligned}
& \varphi_{i}^{*}=\bar{a}_{i}+\frac{R}{2 n^{2}}\left(1-\lambda_{i}^{2}\right) \\
& -\frac{R}{n^{2}}\left\{\frac{\left[(n-1)^{2}(n-2)+1\right] \Delta_{1}}{(n-1)^{2}(n-2)}+\frac{n \Delta_{2}}{(n-1)}-\frac{\left[(n-1)^{2}(n-2)+2\right] \Delta_{1}^{2}}{2(n-1)^{2}(n-2)}-\frac{n \Delta_{1} \Delta_{2}}{(n-1)}\right. \\
& \left.-\frac{n \Delta_{2}^{2}}{2(n-2)}+\frac{\lambda_{i} \Delta_{1}}{(n-1)(n-2)}\right\} .
\end{aligned}
$$

If investors do not act as price takers, there will always be some utility decreasing distortion in risk taking. Investors with a stronger initial imbalance $\left|\xi_{i}\right|$ suffer more heavily than investors whose initial portfolios are already close to optimal risk sharing. Without the ECB's purchases, the loss in utility is the same for buyers and sellers, i.e. the sign of the distortion does not matter.

The curly bracket reveals the additional utility loss induced by the ECB's demand. The additional loss is strictly positive. ${ }^{12}$ Furthermore, the effects of the ECB's purchases are neither symmetric with respect to sellers or buyers nor to the timing.

In addition to the results for a neutral investor with $\lambda_{i}=0$, a further effect comes into place if there is an initial imbalance as represented by $\lambda_{i}$. Obviously, investors with $\lambda_{i}>0$, i.e. the buyers, suffer a higher loss than the sellers who are characterized by $\lambda_{i}<0$. This can be traced back to the price change between the periods. Early trades by the ECB imply a price decrease between the periods. Because of the portfolio adjustment rule, the investors' first-period transactions tend to be higher than the second-period transactions. Therefore, decreasing prices hurt buyers in an additional way. This relationship can be most easily seen for "strong buyers" (with $\xi_{i}>\frac{\Delta_{1}}{n}$ ) who buy in the first period and sell in period 2. Nevertheless, even "weak buyers" (with $0<\xi_{i}<\frac{\Delta_{1}}{n}$ ) suffer from buying more at the high price and buying less at the low price. The opposite is true for sellers.

Result 2 (Redistribution) Early trading by the ECB implies some (relative) redistribution from buyers to sellers compared to the case of late trading.

\footnotetext{
11 We definitely prefer the term "utility" to the more comprehensive expression "welfare". The latter might be misleading for two reasons: First, we conduct a partial analysis neglecting real effects of an increase in asset prices (decrease in interest rates). Second, even within a partial analysis the investors' losses correspond with some gains for the ECB. These gains, however, cannot be valued adequately without an assumption of the ECB's preferences, which definitely lies beyond the scope of our paper. For an interesting approach to re-transferring gains from banks to investors-though in a quite different context-see Kruschwitz et al. (2019).

12 The additional loss can be shown to be a quadratic-concave function in $\Delta_{1}$ and $\Delta_{2}$ which is characterized by non-negative values and positive partial derivatives at the lower bounds of its domain and positive values at the upper bound.
} 


\section{Price Impact of Different Timing Strategies by the ECB}

Now we discuss the impact of the ECB's timing strategy on the different endogenous variables. The effects on the investors' equilibrium portfolios have already been discussed in Sect. 3. Therefore, in the following, we focus on equilibrium prices. We compare the results for the two extreme timing strategies, given a fixed total $\Delta$ of additional demand:

- "Late": The ECB only buys in period 2 so that $\Delta_{2}=\Delta$ and $\Delta_{1}=0$.

- "Early": The ECB only purchases in period 1 so that $\Delta_{1}=\Delta$ and $\Delta_{2}=0$.

As has been explained in the introduction, this elementary distinction allows for analyzing present pricing effects (impact of $\Delta_{1}$ on $p_{1}$ and of $\Delta_{2}$ on $p_{2}$ ), effects of former trading on present prices (impact of $\Delta_{1}$ on $p_{2}$ ), as well as announcement effects (impact of $\Delta_{2}$ on $p_{1}$ ).

For the considered cases we obtain the second-period equilibrium prices:

$$
\begin{aligned}
& \text { Late } p_{2}^{*}=\mu-\frac{1}{n}\left(R-\delta_{22} \Delta\right), \\
& \text { Early } p_{2}^{*}=\mu-\frac{1}{n}\left(R-\delta_{12} \Delta\right),
\end{aligned}
$$

Whenever the ECB purchases a strictly positive net amount of risky assets, the equilibrium price $p_{2}^{*}$ increases. This effect is plausible due to the shortage of available units for the investors. In case of an early trade by the ECB, the second-period price is only affected by the reduction of free float $\left(\delta_{12}=R\right)$. In case of a late trade, we see a stronger increase in $p_{2}^{*}\left(\delta_{22}>\delta_{12}\right)$. The investors actually have to be motivated to forgo earned risk premia by paying a higher price.

Result 3 (Impact on Second-Period Price) A certain demand of the ECB has a stronger impact on the second-period price, when trades take place late.

At the end of period 1, we obtain the following equilibrium prices:

$$
\begin{aligned}
& \text { Late } p_{1}^{*}=\mu-\frac{1}{n}\left(R-\delta_{21} \Delta\right), \\
& \text { Early } p_{1}^{*}=\mu-\frac{1}{n}\left(R-\delta_{11} \Delta\right),
\end{aligned}
$$

The driving force for the interpretation of these results is the relation $\delta_{21}>\delta_{11}$. A marginal unit traded by the ECB has a more severe effect on $p_{1}^{*}$ when trading takes place late instead of early. The mere anticipation of trades in the less liquid second-period trading round has a stronger price impact than the actual early demand in period 1. This remarkable economic characteristic allows us to extend Result 3 to the prior trading period:

Result 4 (Impact on First-Period Price) A credible announcement of the ECB to trade at a later date has a stronger price impact on the price $p_{1}^{*}$ than an immediate trade. 
The price changes $p_{2}^{*}-p_{1}^{*}$ are as follows:

Late $p_{2}^{*}-p_{1}^{*}=\frac{1}{n}\left(\delta_{22}-\delta_{21}\right) \Delta$,
Early $p_{2}^{*}-p_{1}^{*}=\frac{1}{n}\left(\delta_{12}-\delta_{11}\right) \Delta$,

The inspection of the crucial differences between the pricing coefficients reveals a price increase over time if the ECB only trades in the second period $\left(\delta_{22}>\delta_{21}\right)$. However, an early demand by the ECB has an opposite effect on the price change and results in a price decline $\left(\delta_{12}<\delta_{11}\right)$. This is because the ECB's early trade imposes an immediate price pressure which is relaxed in period 2. These relations confirm a corollary of results 2 and 3:

Corollary 1 (Price Change Over Time) If the ECB only trades in the last period, the asset price will increase over time. If the ECB, however, only buys assets in the first trading period, the asset price will decline over time.

Fig. 2 summarizes the previously described price relationships. For a late demand of the ECB, the equilibrium asset prices in both periods are higher than the equilibrium prices resulting from early demand. This characteristic follows from the derived properties of the $p_{t}^{*}(t=1,2)$.

The different signs of the price effects of early and late trades raise the question if the two effects may counterbalance each other. Indeed, if the ECB splits its overall demand $\Delta$ over the two time periods accordingly into

$$
\begin{aligned}
& \Delta_{1}=\frac{\left(\delta_{22}-\delta_{21}\right)}{\left(\delta_{11}-\delta_{12}\right)+\left(\delta_{22}-\delta_{21}\right)} \Delta=\frac{n-1}{n} \Delta \text { and } \\
& \Delta_{2}=\frac{\left(\delta_{11}-\delta_{12}\right)}{\left(\delta_{11}-\delta_{12}\right)+\left(\delta_{22}-\delta_{21}\right)} \Delta=\frac{1}{n} \Delta,
\end{aligned}
$$

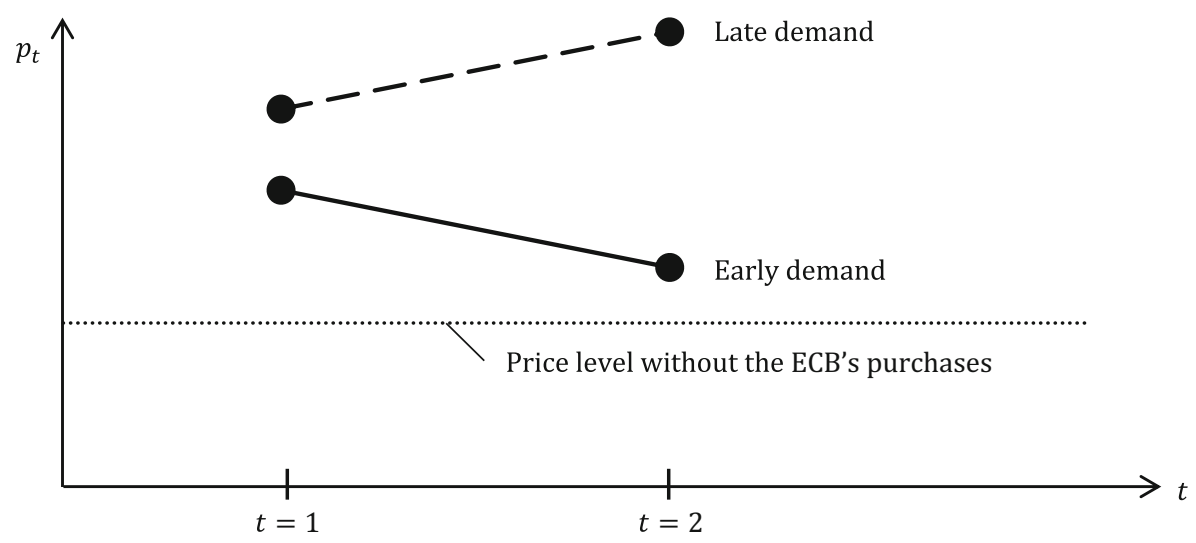

Fig. 2 Price changes in the respective cases 
the respective price effects cancel out and the price remains constant. To reach this effect, the ECB has to purchase more securities in the early stage than in the late stage because early trades have less impact on the price. Even though the price remains constant, it will be above the constant level that we could observe if the ECB was not present in the bond market (cf. eqs. (9)). This results from the fact that the ECB actually withdraws securities from the market.

Corollary 2 (No Price Change) An appropriate division of the ECB's overall demand prevents a price change over time.

\section{A Generalization}

Given a two-period model, we might imagine that investors receive a part of the information on the asset value at the end of period 1. Apparently, the liquidity (i.e. a lower $\beta_{t}$ at trading date $\mathrm{t}$ ) is a major driver of demand functions and equilibrium prices. While liquidity increases if there is a subsequent trading opportunity, it suffers from a higher uncertainty about the asset. As a consequence, the important relation $\beta_{1}<\beta_{2}$ might no longer be valid when a major part of risk is reduced between the two trading dates so that there is (hardly) any risk left in the second period.

We introduce this idea to the model by assuming that the risky asset's value evolves in two steps, i.e.

$$
\widetilde{v}=\mu+\widetilde{\varepsilon}_{1}+\widetilde{\varepsilon}_{2}
$$

where the $\widetilde{\varepsilon}_{t}$ are uncorrelated noise variables $N \sim\left(0 ; \sigma_{t}^{2}\right)$ revealed at the end of period $t(t=1,2)$. Predominantly and quite plausible, this approach has been included in the accounting literature (e.g., Christensen and Feltham 2003, p. 243) and the literature on market microstructure with insider trading (e.g., Hirth 1997).

The observation of $\varepsilon_{1}$ at $t=1$ has two implications on second-period decision making: the conditional expectation on $\widetilde{v}$ is adjusted to the observable realization $\mu+\varepsilon_{1}$ and some share $\alpha$ of the overall ex-ante risk $\operatorname{Var}\left\{\widetilde{\varepsilon}_{1}+\widetilde{\varepsilon}_{2}\right\}$ has already been eliminated. We parameterize the latter aspect using the notation $\sigma_{1}^{2}=\alpha \sigma^{2}$ and $\sigma_{2}^{2}=(1-\alpha) \sigma^{2}$ where $\alpha$ reflects the share of overall risk being settled in period 1 . Thus, the main part of the paper analyzes the special case of $\alpha=0$. We do not go through the derivations, again, but just report the results and comment on it.

1. The ECB's additional demand $\Delta_{t}$ still causes just a vertical shift of the demand functions $x_{i t}\left(p_{t}\right)$.

2. Neither the portfolio adjustment rule $(q)$ nor the optimum equilibrium portfolios $\left(x_{i t}^{*}\right)$ depend on $\alpha$. 
3. The market liquidity $\beta_{t}$ is affected by the timing of the risk:

$$
\begin{array}{cc}
\varepsilon_{2} \text { only }(\alpha=0) & \varepsilon_{1} \text { and } \varepsilon_{2}(\alpha>0) \\
\beta_{1}=\frac{R q^{2}}{n-2} & \widehat{\beta}_{1}=\frac{R\left(\alpha+(1-\alpha) q^{2}\right)}{n-2} \\
\beta_{2}=\frac{R}{n-2} & \widehat{\beta}_{2}=\frac{R(1-\alpha)}{n-2}
\end{array}
$$

The early settlement of some part $\alpha$ of the uncertainty has a different impact on the two period's liquidity. While the second-period liquidity is enhanced $\left(\widehat{\beta}_{2}<\beta_{2}\right)$, the first-period liquidity decreases $\left(\widehat{\beta}_{1}>\beta_{1}\right)$. Further, while liquidity is decreasing over time with $\alpha=0$, in the general approach there is some $\alpha^{*}=\frac{1-q^{2}}{2-q^{2}}\left(\frac{3}{7}<\alpha^{*}<\frac{1}{2}\right)$, such that $\widehat{\beta}_{1}>\widehat{\beta}_{2}$ for all $\alpha>\alpha^{*}$ which reverses the evolution of the liquidity over time. The liquidity in a certain period most of all reflects the share of risk being settled within this period. The more risk is settled in a certain period ( $\alpha$ in period $1,(1-\alpha)$ in period 2$)$, the lower is market liquidity in this particular point in time. If, e.g., there were no residual risk in period $2(\alpha=1)$, the market would be perfectly liquid. The first period's liquidity additionally but to a smaller extent reflects the anticipation of the second period's trades $\left((1-\alpha) q^{2}\right)$. As the relative liquidity in the two periods has been shown to be an important determinant of the ECB's trading price impact, the observation may have consequences for the asset prices.

4. The pricing coefficients $\delta_{s t}$ of the ECB's trades crucially depend on the timing of risk settling. We have

$$
\begin{array}{lcc} 
& \varepsilon_{2} \text { only }(\alpha=0) & \varepsilon_{1} \text { and } \varepsilon_{2}(\alpha>0) \\
\delta_{11} & R+\beta_{1} & R+\widehat{\beta}_{1} \\
\delta_{12} & R & (1-\alpha) R \\
\delta_{21} & R+(1-q) \beta_{2} & (1-\alpha) R+(1-q) \widehat{\beta}_{2} \\
\delta_{22} & R+\beta_{2} & (1-\alpha) R+\widehat{\beta}_{2}
\end{array}
$$

The relation of the equilibrium price sensitivities $\delta_{\mathbf{2 2}}>\delta_{\mathbf{2 1}}>\delta_{\mathbf{1 2}}$ is not affected by the way uncertainty is resolved over time. The ordering of $\delta_{\mathbf{1 1}}$, however, may change. Now, $\delta_{\mathbf{1 1}}$ may exceed $\delta_{\mathbf{2 1}}$ and even $\delta_{\mathbf{2 2}}$. Looking at the different results, corollaries and lemmas from Sects. 3 and 4, only result 4 is affected to some extent: For a small part $\alpha$ of uncertainty being resolved early, late trades by the ECB still have a stronger impact on $p_{1}$ than early trades, while for a substantial part of uncertainty being resolved early, i.e. $\boldsymbol{\alpha}$ close to one, the result is reversed.

\section{Conclusion}

If a market participant takes some units of an asset permanently from the market, the asset price increases due to the reduced number of assets held by other investors. This is the elementary logic behind the ECB's asset purchase programme. In a perfect market, there is no further effect. Of course, investors as a whole bear less risk and 
participate to a reduced extent in the risk premium earned which on balance results in a reduced utility. Within the group of investors, there are no further distortions. ${ }^{13}$

The story becomes more interesting if markets are not perfectly liquid. We, therefore, introduce an equilibrium asset pricing model with imperfect competition, preventing the investors to adjust their portfolios according to the optimal risk-allocation rule. The interplay of the ECB's purchase programme and imperfect competition yields interesting results:

- The ECB's timing strategy gains importance. Compared to early trades, late trades lead to higher prices and a price increase over time.

- Market liquidity decreases as time approaches the security's maturity. As a remarkable implication of this effect, the anticipation of ECB-transactions in the second period has a stronger impact on the first-period price than the presence of first-period additional demand. Both relations require that no or only a minor part of the asset's risk is settled between the trading dates. Otherwise, if a major part of the risk is revealed between the trading dates, the EBS's impact on equilibrium prices for a late trade can be less pronounced than early trades.

- Investors are affected differently, depending on their initial portfolios. While every investor incurs losses induced by the ECB's additional demand, an early additional demand by the ECB comes along with higher losses for buyers than for sellers.

- The price effect of the ECB's transactions exceeds the mere unit effect.

Thus, we finally conclude that imperfect competition should regularly be included in capital market models. While imperfect competition is relevant per se, the explanatory power increases even more given some distortions stemming from whatever reason. Emphasizing this point is not just for presenting interesting results. Rather, it should be acknowledged that real markets are characterized by imperfect competition. This, a forteriori, holds true for bond markets dominated by a limited number of large institutional investors.

Acknowledgments We are very grateful for several helpful suggestions made by Andreas Löffler who discussed our paper at the GEABA symposium 2019 in Vallendar, as well as the many further constructive comments throughout the referee process of the SBR. Moreover, the paper has benefitted from fruitful discussions with Wolfgang Breuer, Hans Hirth, and, in particular, Manfred Stadler.

Funding Open Access funding provided by Projekt DEAL.

Open Access This article is licensed under a Creative Commons Attribution 4.0 International License, which permits use, sharing, adaptation, distribution and reproduction in any medium or format, as long as you give appropriate credit to the original author(s) and the source, provide a link to the Creative Commons licence, and indicate if changes were made. The images or other third party material in this article are included in the article's Creative Commons licence, unless indicated otherwise in a credit line to the material. If material is not included in the article's Creative Commons licence and your intended use is not permitted by statutory regulation or exceeds the permitted use, you will need to obtain permission directly from the copyright holder. To view a copy of this licence, visit http://creativecommons.org/licenses/by/4. $0 /$.

13 The implications can easily be derived from our model by letting $\beta_{t}=q_{t}=0(t=1,2)$. 


\section{Appendix}

Solving for the Demand Parameters $\beta_{t}$ and the Portfolio Adjustment Variables $q_{t}$

Aggregating the optimal individual demand (2) for all investors $i \neq k$, we obtain

$$
\sum_{i \neq k} x_{i 2}=\sum_{i \neq k} \frac{\left(\mu-p_{2}\right)+x_{i 1} \beta_{2}}{R+\beta_{2}} .
$$

Using the market clearing conditions gives

$$
\left(1-x_{k 2}\right)=(n-1) \frac{\mu-p_{2}}{R+\beta_{2}}+\left(1-x_{k 1}\right) \frac{\beta_{2}}{R+\beta_{2}}
$$

and finally

$$
p_{2}=\mu-\frac{1}{n-1}\left(\left(R+\beta_{2}\right)\left(1-x_{k 2}\right)-\beta_{2}\left(1-x_{k 1}\right)\right) .
$$

For any investor $k$, the derivative reads

$$
\frac{\partial p_{2}}{\partial x_{k 2}}=\frac{1}{n-1}\left(R+\beta_{2}\right) \text {. }
$$

It should be emphasized that this equation holds irrespective of some activity or absence of the ECB (cf. Sect. 4). Equating the derivative to the definition

$$
\beta_{2} \equiv \frac{\partial p_{2}}{\partial x_{k 2}}
$$

leads to the equilibrium value of

$$
\beta_{2}=\frac{R}{n-2}
$$

so that

$$
q_{2} \equiv \frac{\partial x_{i 2}}{\partial x_{i 1}}=\frac{\beta_{2}}{R+\beta_{2}}=\frac{\frac{R}{n-2}}{R+\frac{R}{n-2}}=\frac{1}{n-1} .
$$

Within the first period, any investor takes security holdings of

$$
x_{i 1}\left(p_{1}\right)=\frac{\mu-p_{1}+\bar{x}_{i 0} \beta_{1}}{\beta_{1}+R q_{2}^{2}}-\frac{1}{n} \frac{R\left(1-q_{2}^{2}\right)}{\beta_{1}+R q_{2}^{2}} .
$$


The same procedure as developed for period 2 now reads

$$
\begin{aligned}
& \sum_{i \neq k} x_{i 1}=\sum_{i \neq k}\left(\frac{\mu-p_{1}+\bar{x}_{i 0} \beta_{1}}{\beta_{1}+R q_{2}^{2}}-\frac{1}{n} \frac{R\left(1-q_{2}^{2}\right)}{\beta_{1}+R q_{2}^{2}}\right) \\
& \left(1-x_{k 1}\right)=(n-1) \frac{\mu-p_{1}}{\beta_{1}+R q_{2}^{2}}+\left(1-\bar{x}_{k 0}\right) \frac{\beta_{1}}{\beta_{1}+R q_{2}^{2}}-(n-1) \frac{1}{n} \frac{R\left(1-q_{2}^{2}\right)}{\beta_{1}+R q_{2}^{2}} \\
& p_{1}=\mu-\frac{1}{n-1}\left(\left(\beta_{1}+R q_{2}^{2}\right)\left(1-x_{k 1}\right)+\beta_{1}\left(1-\bar{x}_{k 0}\right)-(n-1) \frac{1}{n} R\left(1-q_{2}^{2}\right)\right) \\
& \beta_{1} \equiv \frac{\partial p_{1}}{\partial x_{k 1}}=\frac{1}{n-1}\left(\beta_{1}+R q_{2}^{2}\right),
\end{aligned}
$$

so that

$$
\beta_{1}=\frac{R}{(n-1)^{2}(n-2)} .
$$

\section{Defining}

$$
q_{1} \equiv \frac{\partial x_{i 1}}{\partial \bar{x}_{i 0}}=\frac{\beta_{1}}{\beta_{1}+R q_{2}^{2}}=\frac{\frac{R}{(n-1)^{2}(n-2)}}{\frac{R}{(n-1)^{2}(n-2)}+\frac{R}{(n-1)^{2}}}=\frac{1}{n-1},
$$

we finally see that the portfolio adjustment variable is the same for both periods: $q_{1}=q_{2}=q$.

\section{Solving the General Model With the ECB}

We start with the investors' first-order condition

$$
\frac{\partial \varphi_{i}}{\partial x_{i 2}}=\left(\mu-p_{2}\right)-R x_{i 2}-\left(x_{i 2}-x_{i 1}\right) \beta_{2}=0
$$

and solve for the second-period demand function

$$
x_{i 2}\left(p_{2}, x_{i 1}\right)=\frac{\mu-p_{2}+x_{i 1} \beta_{2}}{R+\beta_{2}} .
$$

The first-order condition aggregated for the investors reads:

$$
\sum_{i=1}^{n} \frac{\partial \varphi_{i}}{\partial x_{i 2}}=n\left(\mu-p_{2}\right)-R \underbrace{\sum_{i=1}^{n} x_{i 2}}_{=1-\Delta_{1}-\Delta_{2}}-\beta_{2} \underbrace{\sum_{i=1}^{n}\left(x_{i 2}-x_{i 1}\right)}_{1-\Delta_{1}-\Delta_{2}-\left(1-\Delta_{1}\right)=-\Delta_{2}}=0 .
$$


Solving this equation for the second-period price leads to

$$
p_{2}^{*}=\mu-\frac{1}{n}\left(R-R \Delta_{1}-\left(R+\beta_{2}\right) \Delta_{2}\right) \text {. }
$$

We can directly compute the equilibrium holdings by inserting the equilibrium market price into the demand function:

$$
x_{i 2}^{*}\left(x_{i 1}\right)=\frac{1-\Delta_{1}}{n}(1-q)+x_{i 1} q-\frac{\Delta_{2}}{n} .
$$

In order to derive the corresponding quantities for the first period, we can substitute the equilibrium price $p_{2}^{*}$, the optimal holdings $x_{i 2}^{*}\left(x_{i 1}\right)$ and $q_{2} \equiv \frac{\partial x_{i 2}}{\partial x_{i 1}}$ into the certainty equivalent and take the following first order condition for $x_{i 1}$ :

$$
\frac{\partial \varphi_{i}}{\partial x_{i 1}}=\mu-(1-q) \frac{1}{n}\left(R-R \Delta_{1}-\left(R+\beta_{2}\right) \Delta_{2}\right)-p_{1}-\beta_{1}\left(x_{i 1}-\bar{x}_{i 0}\right)-R q x_{i 2}=0 .
$$

Inserting for $x_{i 2}$ yields the demand function

$$
x_{i 1}\left(p_{1}\right)=\frac{\mu-p_{1}+\bar{x}_{i 0} \beta_{1}}{\beta_{1}+R q^{2}}-\frac{1}{n} \frac{\left(1-q^{2}\right) R}{\beta_{1}+R q^{2}}+\frac{\Delta_{1}}{n} \frac{\left(1-q^{2}\right) R}{\beta_{1}+R q^{2}}+\frac{\Delta_{2}}{n} \frac{(1+q) R}{\beta_{1}+R q^{2}} .
$$

Only a constant is added to the equation from the reference model. The interaction between the initial portfolio, current price and terminal portfolio remains unaffected. Summing up over the $n$ investors, we obtain

$$
\begin{aligned}
& n\left(\mu-p_{1}-(1-q) \frac{1}{n}\left(R-R \Delta_{1}-\left(R+\beta_{2}\right) \Delta_{2}\right)\right)-\beta_{1} \underbrace{n}_{\left(1-\Delta_{1}\right)-1=-\Delta_{1}}\left(x_{i 1}-\bar{x}_{i 0}\right) \\
& -R q_{2} \underbrace{\sum_{i=1}^{n} x_{i 2}}_{=1-\Delta_{1}-\Delta_{2}}=0 .
\end{aligned}
$$

We can solve for the first-period price

$$
p_{1}^{*}=\mu-\frac{1}{n}\left\{R-\left(R+\beta_{1}\right) \Delta_{1}-\left(R+(1-q) \beta_{2}\right) \Delta_{2}\right\} .
$$

The optimal first-period holdings of the risky asset amount to

$$
x_{i 1}^{*}\left(\bar{x}_{i 0}\right)=\frac{1}{n}-\xi_{i} q-\frac{\Delta_{1}}{n} .
$$

The approach to solving for the price differences and for the investors' utility is obvious even though the derivations for the utility might be a bit lengthy. 


\section{References}

Blinder, A.S., M. Ehrmann, M. Fratzscher, J. De Haan, and D.-J. Jansen. 2008. Central bank communication and monetary policy: a survey of theory and evidence. Journal of Economic Literature 46:910-945.

Christensen, P.O., and G.A. Feltham. 2003. Information in markets. Vol. I. Boston: Kluwer.

Heumann, C. 2007. Asset pricing with imperfect competition and endogenous market liquidity. Ph.D. dissertation. Mannheim: University of Mannheim.

Hirth, H. 1997. Handelsfrequenz und Nichtmengenanpassung. Kredit und Kapital 30:250-275.

Hirth, H., and M. Walther. 2018. Strategic effects between Price-takers and Non-price-takers. The B.e. Journal of Theoretical Economics 18(2):1-18.

Klein, P. 2018. Time consistency of monetary and fiscal policy. In The new Palgrave dictionary of economics, 3rd edn., ed. Macmillan Publishers. London: Palgrave Macmillan.

Kruschwitz, L., A. Löffler, and D. Lorenz. 2019. Divergent interest rates in the theory of financial markets. Quarterly Review of Economics and Finance 71:48-55.

Kyle, A.S. 1985. Continuous auctions and insider trading. Econometrica 53:1315-1335.

Kyle, A.S. 1989. Informed speculation with imperfect competition. Review of Economic Studies 56: 317-356.

Lindenberg, E.B. 1979. Capital market equilibrium with price affecting institutional investors. In Portfolio theory 25 years later, ed. E.J. Elton, M.J. Gruber, 109-124. Amsterdam: North-Holland.

Merton, R.C. 1973. An intertemporal capital asset pricing model. Econometrica 41:867-887.

Mossin, J. 1973. Theory of financial markets. Englewood Cliffs: Prentice Hall.

Rudolph, B. 1982. Portefeuille- und Aktienkursbildung bei monopolistischem Anlegerwettbewerb. Zeitschrift für Betriebswirtschaft 52:471-490.

Sharpe, W.F. 1964. Capital asset prices. A theory of market equilibrium under conditions of risk. Journal of Finance 19:425-442.

Spiegel, M., and A. Subrahmanyam. 1992. Informed speculation and hedging in noncompetitive securities markets. Review of Financial Studies 5:307-329.

Stapleton, R.C., and M.G. Subrahmanyam. 1978. A multiperiod equilibrium asset pricing model. Econometrica 46:1077-1096.

Subrahmanyam, A. 1991. Risk aversion, market liquidity, and price inefficiency. Review of Financial Studies 4:417-441.

Wilson, R.B. 1968. The theory of syndicates. Econometrica 36:119-132.

Publisher's Note Springer Nature remains neutral with regard to jurisdictional claims in published maps and institutional affiliations. 